Original paper

\title{
Infodemic Emergency in Italy: A Longitudinal Analysis of the Web Interest in Sources of Dis-Misinformation, Epidemiologically Dangerous Behaviors, and Vaccine Hesitancy During COVID-19
}

Alessandro Rovetta

\section{Correspondence}

Alessandro Rovetta

R\&C Research Group, Bovezzo (BS), Italy

ORCID: https://orcid.org/0000-0002-4634-279X

WoS ResearcherID: AAT-9063-2020

Email: rovetta.mresearch@gmail.com

Telephone: +393927112808

\begin{abstract}
This paper investigates the web interest of Italian users in sources of COVID-19 dis-misinformation and assumption of behaviors in contrast to the anti-pandemic vaccination regulations. Infodemic keywords have been mined and verified thanks to the fact-checking websites "Bufale.net" and "Butac.it" and then searched on Google Trends. Multi-comparative tests and linear regressions were employed to compare the relative search volumes of the pre-pandemic (2017-2020) and postpandemic (2020-2022) periods. These findings reveal a drastic and widespread growth in the web interest of Italian netizens towards sources of fake news and illegal and epidemiologically risky practices such as the purchase of counterfeit green passes. Among the investigated keywords, the web interest in disinformation channels such as "ByoBlu" and "Radio Radio" recorded the most significant relative increase, especially during the end of 2021 and the beginning of 2022. The relative search volume towards keywords such as "buy green pass," "unlimited green pass," (buy green pass-related query), "fake green pass cost," "fake green pass where to find it" increased from $40 \%$ to $350 \%$ during the first week of February 2022. Other relevant queries in the same period were "create fake green pass," "how to create fake green pass," "how to have fake green pass" and "fake qr code green pass". Moreover, the query "cancel vaccine" reached $7 \%$ of all web searches containing the word "covid" from January 2021 until February 2022. All related queries concerned the cancellation of the COVID-19 vaccine reservation and were reported as "breakout" (i.e., drastically increasing) and were growing during the first week of February 2022 (from 50\% to $110 \%$ ). Nonetheless, this query could be influenced by the number of new COVID-19 infections (cross correlation=0.46, $\mathrm{P}<.001$, lag=4 weeks). In conclusion, government authorities are recommended to take appropriate action to limit these phenomena promptly.
\end{abstract}




\section{Introduction}

Officially started in late December 2019, the COVID-19 pandemic has swept the world causing millions of deaths and the collapse of health and economic systems [1]. As of February 2022, the true global death toll fluctuates between 10 and 20 million victims [2]. Although these numbers are dramatic, implementing pharmaceutical (e.g., vaccines) and non-pharmaceutical (e.g., lockdowns) measures has been fundamental to mitigate the novel coronavirus 2019 damage and spread [3, 4]. Both of these containment approaches are still needed in the current epidemiological scenario [5, 6]. The impact of vaccinations in managing the new epidemic waves of 2021 and 2022 was significant, as the drastic reduction in hospitalizations, ICU admissions, and deaths has allowed hospitals to provide more effective and efficient medical care [7]. This has allowed several nations to limit the number, duration, and extent of lockdowns and save tens of millions of lives. Nonetheless, given the greater infectivity of the new variant of concern Omicron, the use of FFP2 masks (or with similar certification) has been made mandatory for the public in specific social contexts [8]. Although some confuse the concept of endemic with non-dangerousness, we are far from being able to say with a reasonable degree of evidence that the pandemic is about to end [9]. In addition to the primary objective of vaccination equity, fundamental to avoid the appearance of other variants of concern, a further effort will be required to the population in fulfilling the containment measures during the coming months. The psychological distress this entails is an epidemiologically relevant factor since pandemic fatigue reduces compliance and attention to health precautions [10]. Conspiracy hypotheses and movements also represent a severe threat to public health as they diminish adherence to anti-epidemic regulations [11]. Furthermore, the rampant COVID-19 infodemic, fomented even by scientists, politicians, and mass media, has contributed to creating vaccination hesitancy and engaging in various dangerous behaviors [11, 12]. For all these reasons, this situation is delicate and deserves a firm and prompt response from the health authorities right away.

Based on what was discussed above, infodemiology proved to be an essential tool both in the fight against dis-misinformation and the analysis of various medical determinants, including the geographic and temporal distribution of COVID-19 symptoms, fake news, or related psychological disorders [13]. In this scope, Google Trends - a free online infoveillance tool developed by Google has been widely adopted due to its simplicity and the ability to provide results without latency [14, 15]. Despite limitations such as the influence of mass media on netizens' queries and various unpredictable anomalies $[12,16]$, correct use of Google Trends allows the user to obtain valuable information faster than any other method of infodemiological investigation [16-18]. In this regard, the purpose of this research is to exploit Google Trends to explore the web interest of Italian users in sources of dis-misinformation and dangerous behaviors such as the purchase of counterfeit green passes. Specifically, this study aims to outline an updated picture of the Italian infodemiological scenario, essential for elaborating future public health strategies. From now on, all queries associated with personalities and information channels that have shared fake news on COVID-19 will be defined as "infodemic keywords." The selection and search criteria for these keywords are described in the "Methods" section (Data collection). 


\section{Results}

Infodemic keywords relative search volumes (RSVs) of the periods 2017-2020 (pre-pandemic) and 2020-2022 (post-pandemic) were compared to highlight any meaningful changes. The list of queries searched on Google Trends and results of the multi-comparison through Welch t-test are reported in Table 1.

\begin{tabular}{|c|c|c|c|c|c|}
\hline Keyword & Google Trends exact query & Role & Welch $t(d f>100)$ & $\Delta(\mathbf{x} 100)$ & 20-22 ARSV \\
\hline K1 & Sara Cunial ${ }^{*}$ & Politician & 5.6 & 15.9 & 2.1 \\
\hline K2 & Nicola Porro* & Journalist & 12.3 & 5.0 & 14.8 \\
\hline K3 & Stefano Montanari* & Researcher & 6.2 & 3.7 & 6.0 \\
\hline K4 & Luc Montagnier* & Researcher & 4.0 & 17.4 & 3.7 \\
\hline K5 & Alessandro Meluzzi* & Psychiatrist & 9.8 & 4.7 & 4.7 \\
\hline K6 & Diego Fusaro* & Columnist & 6.5 & 0.5 & 5.6 \\
\hline K7 & Balanzoni (Barbara) & Doctor & 7.5 & 26.7 & 4.4 \\
\hline K8 & [Not shown for privacy] & Italian entrepreneur & 5.5 & 5.9 & 0.8 \\
\hline K9 & byoblu & Journalism website & 11.6 & 8.0 & 9.0 \\
\hline K10 & Maurizio Blondet* & Journalist & 11.4 & 0.5 & 8.9 \\
\hline K11 & Francesca Donato* & Politician & 4.4 & 4.4 & 1.8 \\
\hline K12 & Aldo Maria Valli* & Journalist & 5.4 & 0.4 & 2.0 \\
\hline K13 & Marco Tosatti* & Journalist & -1.4 & -0.3 & 0.1 \\
\hline K14 & Imola Oggi* & Journalism website & 11.1 & 2.4 & 1.8 \\
\hline K15 & radio radio & Journalism website & 11.5 & 7.8 & 0.8 \\
\hline K16 & Massimo Mazzucco* & Journalist & 8.0 & 2.4 & 3.3 \\
\hline K17 & luogocomune & Journalism website & 8.0 & 1.4 & 1.5 \\
\hline
\end{tabular}

Table 1. Comparison of the average values of COVID-19 dismisinformation-related RSVs before and after COVID-19 (2017 - 2020 vs $2020-2022$ ). All results except K13 are highly significant (Adjusted $P<.001$ ). Legend: $\mathrm{df}=$ degrees of freedom, $\Delta=$ percentage increase, 20-22 ARSV $=2020-2022$ average relative search volume. Inclusion in the infodemic list is detailed in Supplementary File 1. * Recognized by Google Trends as a public figure. 
Almost all keywords underwent a substantial increase in RSV over the last five years (16/17, 94\%). Figure 1 illustrates the five keywords with an evident level shift in RSV during the COVID-19 pandemic period.

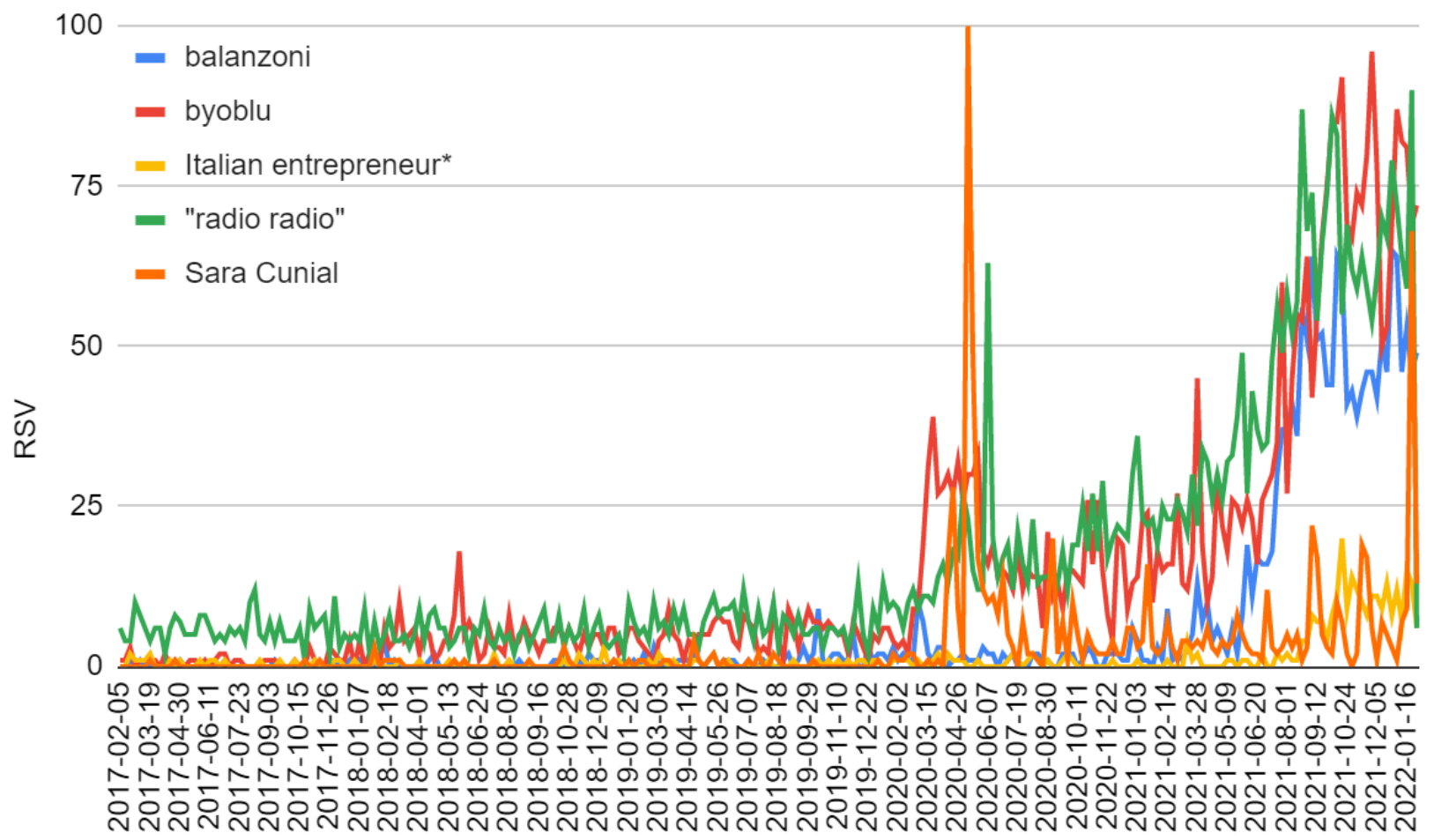

Figure 1. Top 5 dismisinformation-related search volume increases during COVID-19: comparison between February 2017 - December 2019 and January 2020 - first week of February 2022. *This name has been blacked out to protect the individual's identity who is not a public character.

Since the keywords "Nicola Porro" and "Maurizio Blondet" showed trends in the period 2017-2020, ad-hoc evaluation strategies have been adopted. As for the first keyword, Figure 2 displays two different predictions for the 2020-2022 range and the discrepancies recorded with the observed values. The Welch t-test between the populations of the 2017-2020 and 2020-2022 residuals returned a highly significant difference $(t=3.5, \mathrm{P}<.001$, Adjusted $\mathrm{P}=.004)$. In particular, the query recorded an evident level shift during the first COVID-19 wave and then realigned with the prepandemic trend. On the contrary, the query "Maurizio Blondet" was aligned with the 2017-2020 trend until June 2020. Then, after a sharp drop in RSV, it resumed with a double slope trend. Nonetheless, an RSV outlier was identified during the first COVID-19 wave (Figure 3). 


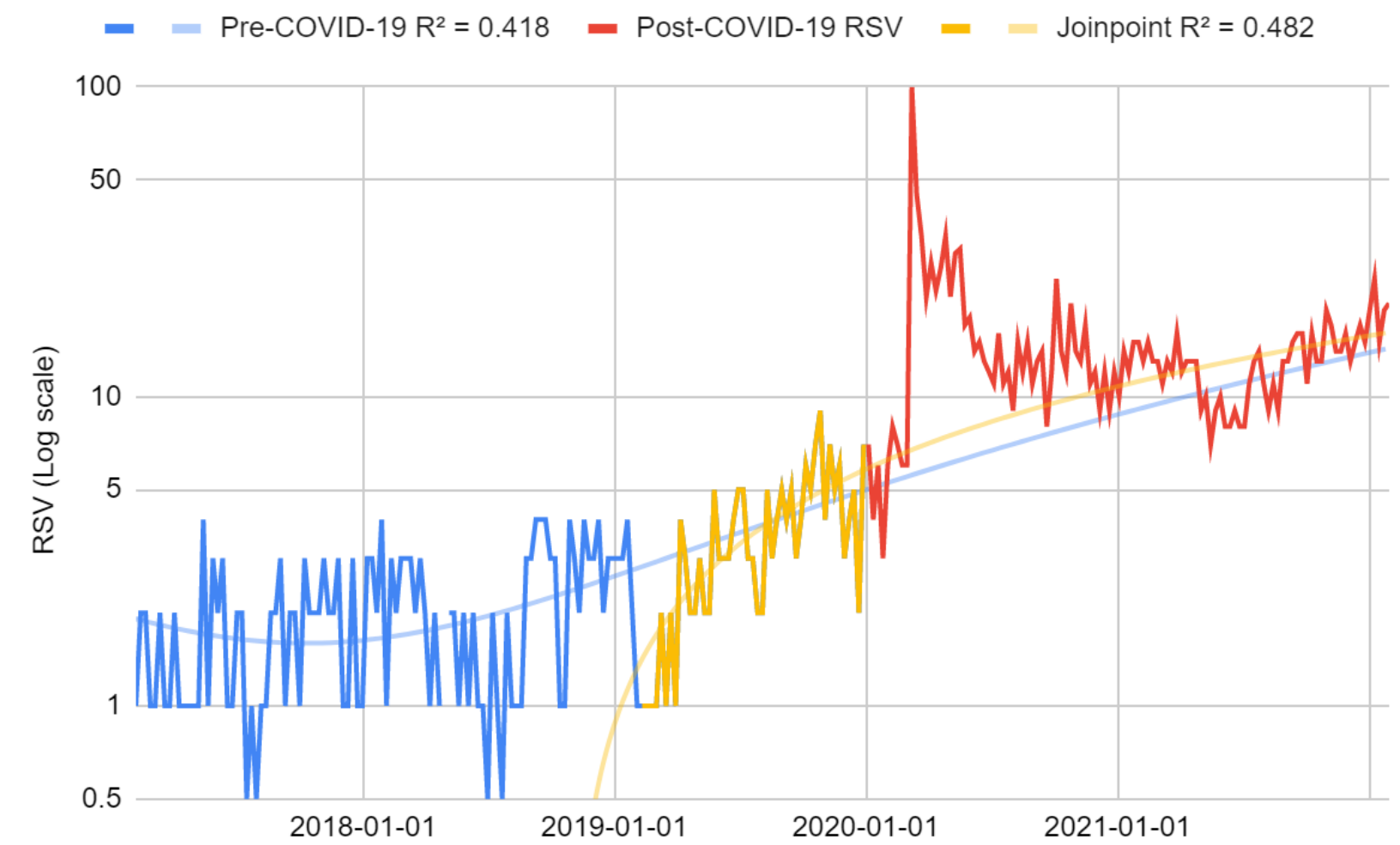

Figure 2. Web interest (RSV) towards the Italian journalist "Nicola Porro," author of numerous conspiracy articles on COVID-19 vaccines and cures (Supplementary File 1). The figure highlights the marked level shift during the COVID-19 first wave in Italy. The yellow line is the joinpoint linear interpolation, while the blue is a quadratic interpolation (2017-2020 = training set, 2020-2022 = prediction). 


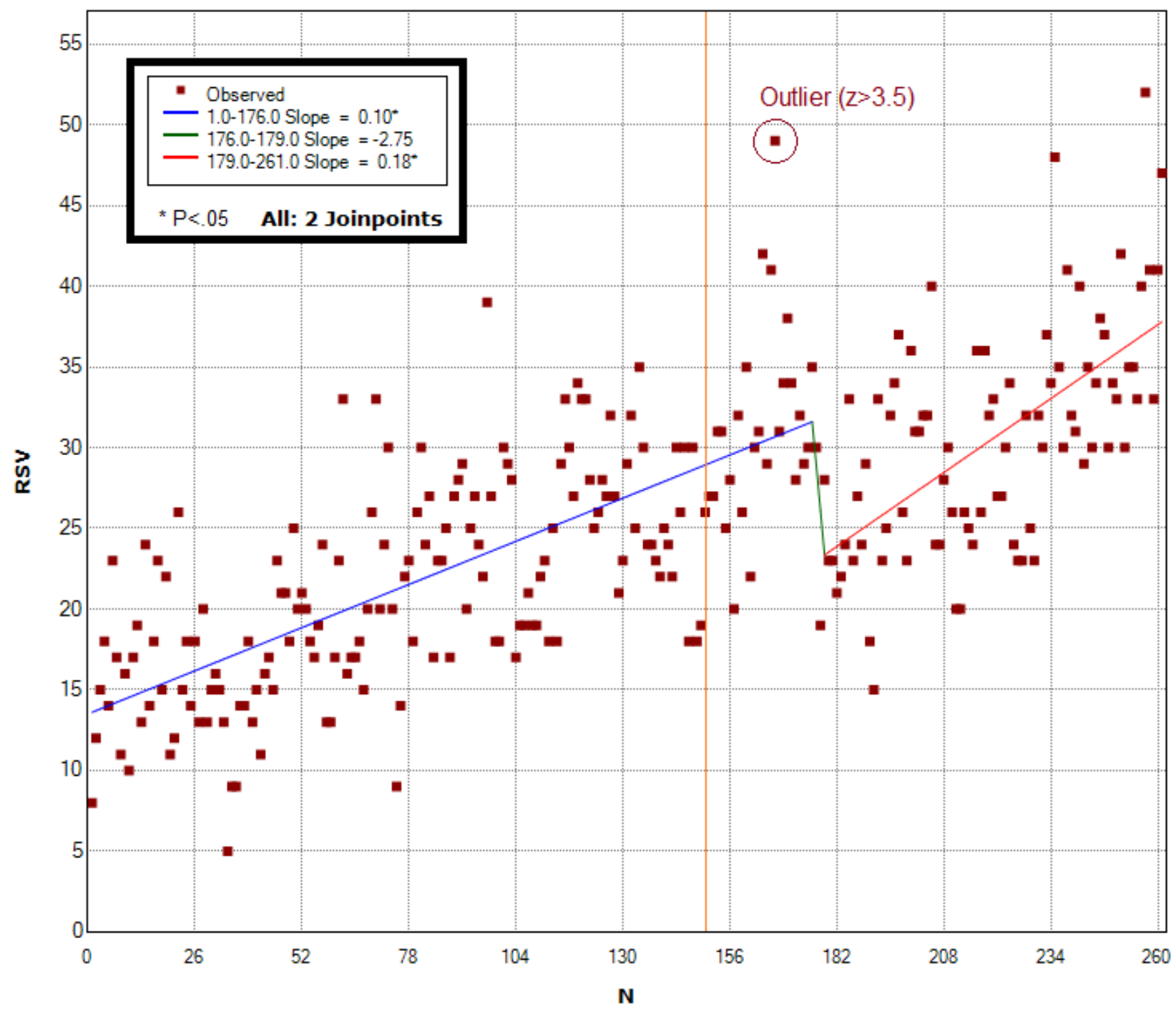

Figure 3. Web interest (RSV) towards the conspiratorial journalist "Maurizio Blondet." The orange line marks December 31, 2019. The interpolation is a weighted BIC3 joinpoint regression with a maximum of 4 joinpoints. Residuals were judged normally distributed (Shapiro-Wilk $\mathrm{P}=.157$ ). Two sided Iglewicz and Hoaglin's robust test for multiple outliers identified only 1 outlier (April 2020) in the distribution of the residuals until June 2020 (first joinpoint).

\section{Regional variability in the web interest towards the top 5 searched infodemic sources}

Table 2 reports the pre and post-pandemic regional web interest in the five queries with the highest average RSVs nationwide. There was a moderate homogeneity in 4 out of 5 keywords, which indicates that the increase in national RSV was equally distributed among the regions. Nonetheless, it is fair to observe that the coefficient of variability decreased while the average RSV increased in 4 out of 5 keywords. The "radio radio" query RSV is a clear outlier, as it became extremely more homogeneous and nationally searched during COVID-19. 


\begin{tabular}{|l|l|l|l|l|l|l|l|}
\hline Keyword & Query & '17-'20 ARSV & '20-'22 ARSV & P-value (P) & Adj. P & '17-‘20 CV\% '20-‘22 CV\% \\
\hline K2 & Nicola Porro & 55 & 59 & .496 & .496 & 40 & 35 \\
\hline K15 & "radio radio" & 15 & 50 & $<.001$ & $<.001$ & 142 & 38 \\
\hline K9 & byoblu & 45 & 58 & .047 & .188 & 47 & 40 \\
\hline K10 & Maurizio Blondet & 58 & 49 & .144 & .432 & 37 & 46 \\
\hline K3 & Stefano Montanari & 51 & 55 & .407 & .814 & 57 & 38 \\
\hline
\end{tabular}

Table 2. Comparison of pre and post-pandemic regional web interest in the five infodemic queries with the highest average RSVs nationwide. ARSV = average relative search volume.

\section{Queries' RSV related to epidemiologically dangerous behavior and vaccine hesitancy}

Italian netizens showed a marked interest in looking for loopholes to avoid COVID-19 vaccination and swabs (Figure 4). In particular, the searches for the "fake green pass," "buy green pass," and "avoid vaccine" queries reveal a strong interest in the economic sanctions, costs, and procedures related to a counterfeit document and a growing fear of vaccination. This also indicates a clear intention to obtain the fake green pass certification (Table 3).

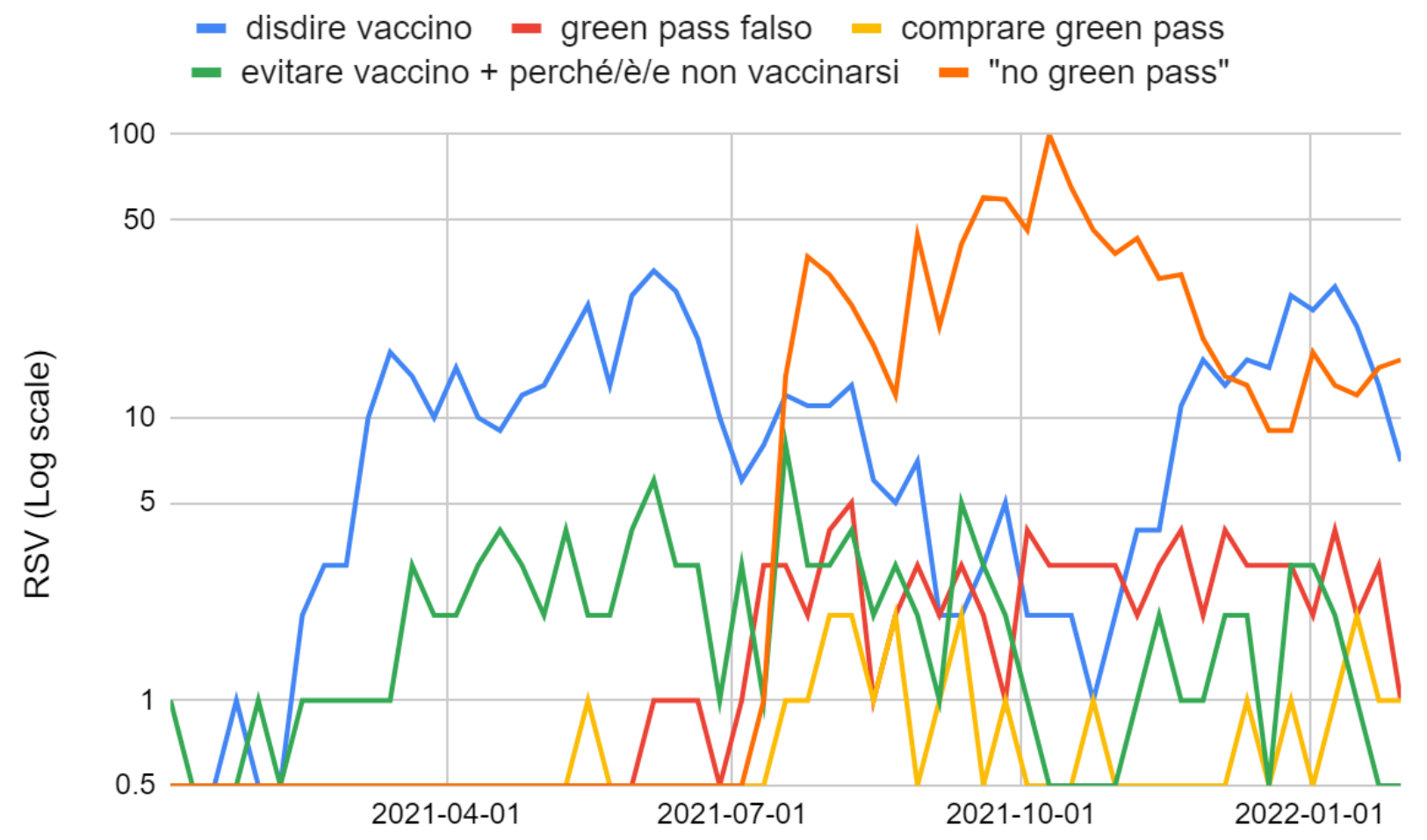

Figure 4. RSV of the "green passo falso" (fake green pass), "comprare green pass" (buy green pass), "perché non vaccinarsi + evitare vaccino" (why not get vaccinated + avoid vaccine), "disdire vaccino" (cancel vaccine), and "no green pass" queries. Investigated period: January 2021 - February 2022. 


\begin{tabular}{|c|c|c|c|}
\hline Query & English translation & Query type & RSV \\
\hline green pass falso sanzioni & green pass false sanctions & Top & 100 \\
\hline sanzioni green pass & green pass sanctions & Top & 100 \\
\hline multa green pass falso & false green pass fine & Top & 56 \\
\hline green pass falso reato & green pass false crime & Top & 54 \\
\hline green pass falso cosa si rischia & false green pass what you risk & Top & 52 \\
\hline qr code green pass falso & qr code green pass fake & Top & 49 \\
\hline green pass falso come fare & fake green pass how to do it & Top & 48 \\
\hline green pass falsi & fake green passes & Top & 48 \\
\hline creare green pass falso & create fake green pass & Top & 43 \\
\hline green pass falso costo & false cost green pass & Top & 16 \\
\hline come creare un green pass falso & how to create a fake green pass & Top & 15 \\
\hline green pass falso dove trovarlo & fake green pass where to find it & Top & 14 \\
\hline come fare un green pass falso & how to make a fake green pass & Top & 12 \\
\hline come avere un green pass falso & like having a fake green pass & Top & 10 \\
\hline green pass illimitato & unlimited green pass & Top & 8 \\
\hline green pass illimitato & unlimited green pass & Rising & $350 \%$ \\
\hline green pass falso dove trovarlo & fake green pass where to find it & Rising & $200 \%$ \\
\hline green pass falso costo & false cost green pass & Rising & $120 \%$ \\
\hline green pass falso reato & green pass false crime & Rising & $50 \%$ \\
\hline green pass falso sanzioni & green pass false sanctions & Rising & $40 \%$ \\
\hline sanzioni green pass & green pass sanctions & Rising & $40 \%$ \\
\hline
\end{tabular}

Table 3. Top and Rising Infodemic Google Trends related queries for the "fake green pass" and "buy green pass" keywords. Investigated period: 2022, February 2-7.

In the first week of February 2022, the fake green pass-related web searches were homogeneous among the Italian regions (ARSV $=63, \mathrm{CV} \%=23 \%$ ). Furthermore, the time series showed periodic daily peaks between $3 \mathrm{AM}$ and $5 \mathrm{AM}$. The "comprare green pass" (buy green pass) query also had significant RSVs. In total, from May 2021 to February 2022, the query "fake green pass + buy green pass" made up, on average, $0.14 \%$ of searches compared to the keyword "covid" and $0.38 \%$ compared to the keyword "green pass." Considering all the anti-green pass and anti-vaccine queries shown in Figure 4, the average RSV reached $1.3 \%$ of the "covid" query and $2.9 \%$ of the "green pass" query. The query "disdire vaccino" (cancel vaccine) reached $6.9 \%$ of the "covid" query and $15.5 \%$ of the "green pass" query from January 2021 to February 2022. The related queries exclusively concerned the procedures for canceling the reservation of the COVID-19 vaccine and were all reported as "breakout" (i.e., an extreme surge). In the first week of February 2022, related queries concerned how to cancel the vaccine reservation in various regions and cities (Table 4). Regionally, the variability was greater than in green pass-related queries (ARSV $=54, \mathrm{CV} \%=53 \%$ ). 


\begin{tabular}{|c|c|c|c|}
\hline Query & English translation & Query type & RSV \\
\hline disdire vaccino covid & cancel covid vaccine & Top & 100 \\
\hline disdire prenotazione vaccino & cancel vaccine reservation & Top & 67 \\
\hline disdire prenotazione vaccino covid & cancel your covid vaccine reservation & Top & 44 \\
\hline come disdire vaccino & how to cancel vaccine & Top & 39 \\
\hline come disdire vaccino covid & how to cancel covid vaccine & Top & 28 \\
\hline disdire appuntamento vaccino & cancel vaccine appointment & Top & 14 \\
\hline come disdire prenotazione vaccino covid & how to cancel covid vaccine booking & Top & 10 \\
\hline disdire vaccino covid lombardia & cancel covid lombardy vaccine & Top & 9 \\
\hline per disdire vaccino & to cancel vaccine & Top & 9 \\
\hline disdire il vaccino & cancel the vaccine & Top & 7 \\
\hline disdire appuntamento vaccino covid & cancel covid vaccine appointment & Top & 6 \\
\hline disdire prenotazione vaccino lombardia & cancel booking of Lombardy vaccine & Top & 6 \\
\hline disdire prenotazione vaccino covid lombardia & cancel booking covid lombardy vaccine & Top & 5 \\
\hline come disdire appuntamento vaccino & how to cancel a vaccine appointment & Top & 5 \\
\hline disdire vaccino covid lazio & cancel covid lazio vaccine & Top & 5 \\
\hline disdire terza dose vaccino & cancel third vaccine dose & Top & 4 \\
\hline come disdire il vaccino & how to cancel the vaccine & Top & 4 \\
\hline disdire vaccino covid veneto & cancel covid veneto vaccine & Top & 4 \\
\hline numero verde per disdire vaccino covid lombardia & toll-free number to cancel the Lombardy covid vaccine & Rising & $110 \%$ \\
\hline disdetta vaccino covid toscana & cancellation of Tuscan covid vaccine & Rising & $100 \%$ \\
\hline numero per disdire vaccino covid lombardia & number to cancel the Lombardy covid vaccine & Rising & $100 \%$ \\
\hline disdire prenotazione vaccino covid milano & cancel booking covid milan vaccine & Rising & $70 \%$ \\
\hline disdire prenotazione vaccino toscana & cancel your Tuscan vaccine reservation & Rising & $60 \%$ \\
\hline disdire prenotazione vaccino covid toscana & cancel the reservation of the Tuscan covid vaccine & Rising & $60 \%$ \\
\hline disdire vaccino covid toscana & cancel Tuscan covid vaccine & Rising & $60 \%$ \\
\hline numero per disdire vaccino covid & number to cancel covid vaccine & Rising & $60 \%$ \\
\hline come si fa a disdire il vaccino & how do you cancel the vaccine & Rising & $50 \%$ \\
\hline numero verde per disdire vaccino covid & toll-free number to cancel the covid vaccine & Rising & $50 \%$ \\
\hline disdire vaccino covid milano & cancel covid milan vaccine & Rising & $50 \%$ \\
\hline disdire prenotazione vaccino covid verona & cancel booking covid verona vaccine & Rising & $50 \%$ \\
\hline come disdire prenotazione vaccino covid toscana & how to cancel your covid tuscan vaccine reservation & Rising & $50 \%$ \\
\hline come disdire vaccino covid milano & how to cancel covid milan vaccine & Rising & $50 \%$ \\
\hline come disdire vaccino covid toscana & how to cancel Tuscan covid vaccine & Rising & $50 \%$ \\
\hline
\end{tabular}

Table 4. COVID-19 vaccines cancellation-related queries during the first week of February 2022. 
However, the number of COVID-19 infections could influence the "cancel vaccine" query since the vaccine cannot be administered to a sick patient. By checking the cross-correlations between the new COVID-19 weekly national cases and the weekly national RSVs, an optimum was found with lag equals 4 weeks (COVID-19 cases predicted RSVs) and Spearman correlation equals $R=0.46(P<.001)$. In contrast, the cross-correlation between the queries "cancel vaccine" and "avoid vaccine + why not get vaccinated" was substantially lower (lag=0 weeks, $R=0.26, P=.060$ ). Among the negative results, it must be highlighted that a detailed comparison of infodemic and dangerous queries between regions was not possible due to Google Trends type 1, 2, and 3 anomalies [16, 17].

\section{Discussion}

This research found a marked and very significant increase in the web interest of Italian users towards known sources of disinformation during COVID-19. The relative search volume grew beyond the predictions made based on the historical analysis of the time series in the previous three years (2017-2020 vs. 2020-2022) in 16 out of 17 keywords. However, the shape and duration of the increases were very different. Specifically, (dis)information channels such as ByoBlu and Radio Radio and other public interest figures such as the politician Sara Cunial and the former Dr. Barbara Balanzoni have recorded both a dizzying increase in RSV during the first wave and a sharp growing trend up to the present day. Keywords such as those relating to journalists and bloggers Nicola Porro and Maurizio Blondet recorded strong trends with localized increases, especially during the first wave. Nonetheless, it is essential to note that COVID-19 has not helped reduce the infodemic phenomenon on any occasion. Other queries, including those concerning Dr. Stefano Montanari and Luc Montagnier, had only localized peaks and no trends. For these reasons, COVID-19 has been a relevant factor for the infodemic spread in Italy, favoring the phenomenon in most cases without ever countering it. As shown in Supplementary File 1, all the characters and websites listed in Table 1 have shared serious fake news about COVID-19. These ranged from the alleged danger and uselessness of vaccines to the mildness of the disease. For these reasons, various measures and reactions have been triggered. Among the most striking examples, we saw the suspension from the medical order of Barbara Balanzoni (former resuscitator anesthetist) and Alessandro Meluzzi (former psychiatrist) due to their no-vax position. Moreover, Dr. Stefano Montanari was denounced by a group of scientists called "Patto Trasversale per la Scienza" for his conspiracy hypotheses on COVID-19 and vaccines, and the ByoBlu YouTube channel has been closed by YouTube for the same reason. Concurrently with this, users showed a growing web interest in illegal practices such as buying or realizing counterfeit green passes. Especially during the first week of February 2022, queries related to costs, procedures, and possible sanctions have soared up to $200 \%$. These findings highlight that the problem is vast (plausibly in the order of millions of queries) and widespread nationwide. Indeed, having reached an RSV equal to $0.14 \%$ of the "covid" keyword (which has an RSV comparable to the top 2021 rising query "vaccine"), the phenomenon assumes a critical epidemiological relevance and denotes a potential issue for future containment strategies. Alongside this, a strong web interest in practices for canceling the booking for COVID-19 vaccination has been observed. Although this result is undoubtedly noteworthy and partly attributable to vaccination hesitancy - as evidenced by the correlated queries "avoid vaccine" and "why not get vaccinated" - the analysis of the determinants is complex since patients recently infected with COVID-19 cannot be vaccinated. On this point, a brief semi-quantitative investigation revealed a 
moderate correlation between the new COVID-19 cases and the queries on vaccine cancellation. Nevertheless, regardless of the reasons, this fact represents an epidemiological situation as the RSV reached $7 \%$ of the "covid" query.

The infodemic problem encompasses a wide variety of psychological and media factors [27]. Fear, anxiety, stress, and fatigue can diminish the rational faculties and exaggerate and distort risk perception $[28,29]$. This can lead, depending on the case, to believing in fake news or vaccination hesitancy [30, 31]. However, such negative emotions also proved helpful in undertaking appropriate hygiene and social distancing measures [32]. Similarly, trust in health authorities is fundamental for the credibility of information and the consequent assumption of non-dangerous behavior [30], but, at the same time, excessive confidence can irrationally decrease risk perception [33]. Hence, there is no simple answer regarding the catalysts of an infodemic or the measures to face it. In addition, conspiracy theorists and even some nationally or internationally renowned newspapers frequently use sensational headlines and wordings, intentionally focused on creating strong emotions like anger or fear $[17,12,34]$. Indeed, the emotional impact on the perception of risk is, on average, much higher than that of a logical argument (e.g., showing examples of damage works better than providing data) [35]. Even the media coverage of the news can unreasonably and unconsciously boost risk perception [36]. A clear example of this was the media hype about the very rare serious side effects of COVID-19 vaccines, perceived by the population as hundreds of times more severe than their true magnitude [34]. In such a scenario, the rising Italian web interest in infodemic sources requires immediate action. In this regard, the author of this paper advocates that a simple information campaign will never be enough to resolve the issue definitively. As a matter of fact, the tendency to believe conspiracy hypotheses is often driven by deeply rooted psychological reasons, including acceptance in certain social contexts, philosophical questioning, pattern recognition, exaggerated defense mechanisms, and even past traumas [27, 37]. Besides, not all scientists have sufficient communication skills [27]. Therefore, as also stressed by the WHO, building resilience to dis-misinformation is a necessary step to counteract the infodemic, and such a practice should start right from preschools.

To the best of the author's knowledge, this is the first research that investigates such a broad spectrum of infodemic sources in Italy and detects a strong web interest in epidemiologically dangerous behaviors such as the purchase of counterfeit COVID-19 green passes. In particular, this study provides an infodemiological framework needed to develop future public health strategies. Furthermore, the research hypotheses have been well targeted based on evidence of another nature (e.g., psychological), thus avoiding the Look-elsewhere effect. Finally, the paper provides two interpretations (one more conservative thanks to the Holm-Bonferroni corrections), decreasing the author's bias and guaranteeing the reader an independent reading of the results. This manuscript has also some weaknesses. In particular, the investigation carried out cannot deduce the exact reasons why users have searched for known sources of disinformation. Therefore, Google Trends is recommended as a complementary tool for sentiment analysis. Furthermore, the Italian internet penetration is between $73 \%$ and $76 \%$ [38, 39], and Google is a search engine used by $95 \%$ of Italian netizens [40]. Therefore, these findings may not represent the interests of a slice of the population between $23 \%$ and $30 \%$. Moreover, internet penetration is partially dependent on age groups and sex [41]. Finally, there are no guarantees that all infodemic sources have been considered. 
In conclusion, this study found a marked and very significant increase in the web interest of Italian netizens in numerous sources of disinformation during the COVID-19 pandemic. Besides, recent queries have been identified that denote the engaging of epidemiologically dangerous behaviors as well as illegal practices, including buying or making counterfeit green passes. Since there are valid reasons in the literature that link the media coverage of fake news to its credibility and impact, it is recommended that health authorities take immediate action to mitigate the phenomenon before it can compromise the success of current and future containment strategies.

\section{Methods}

\section{Data collection}

As done in previous articles, the sources of dismisinformation have been mined from the website "Bufale.net," a renowned Italian anti-hoax website [1, 2]. Additionally, an independent investigation was conducted to verify that these sources were directly associated with COVID-19-related fake news (Supplementary File 1). For this purpose, other fact-checking websites, such as "Butac.it" (known for collaborating with the National Federation of Orders of Physicians and Dentists "FNOMCeO" [3, 4]), have also been consulted. All the keywords of the Bufale.net blacklist were searched on Google Trends on February 4, 2022, with the following settings: Region = Italy, Time range $=$ Past 5 years, Category $=$ All categories, Search type $=$ Web Search. The ".csv" files of the "Subregion" section were downloaded to investigate the regional RSV of the most searched infodemic queries. In this regard, Google Trends related queries were consulted to evaluate the type of web search (e.g., "Montagnier covid") and identify other infodemic sources. The Interest over time RSVs were downloaded in .csv format and imported into Microsoft Excel v.2201. Only keywords with average RSVs>1 were collected (reference keyword: "Sara Cunial"). When the keywords had RSV peaks so high as to reduce the accuracy of Google Trends on the other queries, the recursive collection and renormalization procedure was adopted [17]. Finally, the search for anti-green pass and anti-vaccines keywords on Google Trends was conducted to investigate the web interest in epidemiologically dangerous behavior. In this case, the queries made in the first week of February (when the study was conducted) were also evaluated. Exact keywords are presented in the results. Confirmed cases of COVID-19 were collected by the "Our World in Date" to check for possible confounding factors [23].

\section{Data analysis}

Using a multiple Welch t-test, the average RSVs of each keyword for the periods "January 2017 December 2019" and "January 2020 - early February 2022" were compared. Since the datasets were sufficiently large (N1=152 weeks, N2=109 weeks), the distributive normality was not required (central limit theorem). Furthermore, the Welch t-test performs well even when dealing with heavily skewed datasets [24]. Mean values were preferred over medians since outliers were of interest. By doing so, it was possible to assess whether there was an average increase in web interest in the infodemic sources examined. All the time series in the 2017-2020 timelapse were first graphically inspected to verify the absence of seasonalities. Then the Mann-Kendall test was used to assess trends (a graphical check has also been done). When the Sen's Slope was close to 0 (e.g., <0.01) or the trend significance was very low (e.g., $\mathrm{P}<.100$ ), the series was considered sufficiently stationary (indeed, heteroskedasticity is managed by the Welch t-test). In this case, the Welch t-test made it 
possible to evaluate the impact of COVID-19 on RSV. When trends were identified, and the graphical-qualitative analysis showed evident level shifts or outliers during the first COVID-19 wave, the 2017-2020 time-series data were interpolated with a joinpoint regression. After that, a prediction was made for the period "2020-2022" based on the latest trend detected. Finally, the 2017-2020 and 2020-2022 residuals' populations were compared through a Welch test to highlight any differences. When no evident level shift was found, the joinpoint regression was extended to the entire 2017-2022 time range to highlight any changes in trends caused by the COVID-19 outbreak. In particular, this was done in order to minimize author bias. Iglewicz and Hoaglin's robust test for multiple outliers with $z>3.5$ was applied to the population of residuals to look for possible outliers. Finally, the Mann-Whitney $U$ test $(z)$ was used to compare the regional RSVs of the pre-and post-pandemic periods. Any other ad-hoc tests were specified and fully described in the results.

\section{Additional details on statistical analysis}

Joinpoint regression. The Joinpoint regression program v.4.9.0.0 software was used [25]. The settings have been left to default ones unless otherwise specified.

Multi-comparison adjustment. The adjustment of $\mathrm{P}$-values is a widely debated topic in the scientific community [26]. In this regard, the author of this paper prefers not to use this procedure since the test hypotheses were well-targeted (i.e., the risks of false positives were contained). However, two approaches were employed to ensure the reader can independently read the results: $A 1=$ no adjustment and $\mathrm{A} 2$ = standard Holm-Bonferroni adjustment. Furthermore, P-values were used as graded measures of the evidence against the null hypothesis (assuming that the other assumptions of the tests have been met). Finally, all tools have been provided to conduct the analysis independently.

\section{References}

[1] Coronavirus disease (COVID-19)/Timeline: WHO's COVID-19 response. World Health Organization. URL: https://www.who.int/emergencies/diseases/novel-coronavirus2019/interactive-timeline [accessed 2022-02-08]

[2] Adam D. The pandemic's true death toll: millions more than official counts. Nature. 2022 Jan;601(7893):312-315. doi: 10.1038/d41586-022-00104-8. PMID: 35042997.

[3] Harder T, Külper-Schiek W, Reda S, Treskova-Schwarzbach M, Koch J, Vygen-Bonnet S, Wichmann O. Effectiveness of COVID-19 vaccines against SARS-CoV-2 infection with the Delta (B.1.617.2) variant: second interim results of a living systematic review and meta-analysis, 1 January to 25 August 2021. Euro Surveill. 2021 Oct;26(41):2100920. doi: 10.2807/15607917.ES.2021.26.41.2100920. PMID: 34651577; PMCID: PMC8518304.

[4] Haug N, Geyrhofer L, Londei A, Dervic E, Desvars-Larrive A, Loreto V, Pinior B, Thurner S, Klimek $P$. Ranking the effectiveness of worldwide COVID-19 government interventions. Nat Hum Behav. 2020 Dec;4(12):1303-1312. doi: 10.1038/s41562-020-01009-0. Epub 2020 Nov 16. PMID: 33199859.

[5] Harder T, Külper-Schiek W, Reda S, Treskova-Schwarzbach M, Koch J, Vygen-Bonnet S, Wichmann O. Effectiveness of COVID-19 vaccines against SARS-CoV-2 infection with the Delta (B.1.617.2) variant: second interim results of a living systematic review and meta-analysis, 1 January to 25 
August 2021. Euro Surveill. 2021 Oct;26(41):2100920. doi: 10.2807/15607917.ES.2021.26.41.2100920. PMID: 34651577; PMCID: PMC8518304.

[6] León TM, Vargo J, Pan ES, Jain S, Shete PB. Nonpharmaceutical Interventions Remain Essential to Reducing Coronavirus Disease 2019 Burden Even in a Well-Vaccinated Society: A Modeling Study. Open Forum Infect Dis. 2021 Aug 9;8(9):ofab415. doi: 10.1093/ofid/ofab415. PMID: 34514021; PMCID: PMC8419741.

[7] Liu Q, Qin C, Liu M, Liu J. Effectiveness and safety of SARS-CoV-2 vaccine in real-world studies: a systematic review and meta-analysis. Infect Dis Poverty. 2021 Nov 14;10(1):132. doi: 10.1186/s40249-021-00915-3. PMID: 34776011; PMCID: PMC8590867.

[8] Considerations for the use of face masks in the community in the context of the SARS-CoV-2 Omicron variant of concern. European Centre for Disease Prevention and Control. URL: https://www.ecdc.europa.eu/sites/default/files/documents/Considerations-for-use-of-facemasks-in-the-community-in-the-context-of-the-SARS-CoV-2-Omicron-variant-of-concern.pdf [accessed 2022-02-08]

[9] Adam D. Will Omicron end the pandemic? Here's what experts say. Nature. 2022 Feb;602(7895):20-21. doi: 10.1038/d41586-022-00210-7. PMID: 35102287.

[10] Elia F, Vallelonga F. "Pandemic fatigue" or something worse? Recenti Prog Med. 2020 Dec;111(12):788-789. doi: 10.1701/3509.34972. PMID: 33362178.

[11] Pavela Banai I, Banai B, Mikloušić I. Beliefs in COVID-19 conspiracy theories, compliance with the preventive measures, and trust in government medical officials. Curr Psychol. 2021 May 26:111. doi: 10.1007/s12144-021-01898-y. Epub ahead of print. PMID: 34075284; PMCID: PMC8153526.

[12] Rovetta A, Castaldo L. Influence of Mass Media on Italian Web Users During the COVID-19 Pandemic: Infodemiological Analysis. JMIRx Med. 2021 Oct 18;2(4):e32233. doi: 10.2196/32233. PMID: 34842858; PMCID: PMC8601032.

[13] Tsao SF, Chen H, Tisseverasinghe T, Yang Y, Li L, Butt ZA. What social media told us in the time of COVID-19: a scoping review. Lancet Digit Health. 2021 Mar;3(3):e175-e194. doi: 10.1016/S25897500(20)30315-0. Epub 2021 Jan 28. PMID: 33518503; PMCID: PMC7906737.

[14] Jimenez AJ, Estevez-Reboredo RM, Santed MA, Ramos V. COVID-19 Symptom-Related Google Searches and Local COVID-19 Incidence in Spain: Correlational Study. J Med Internet Res. 2020 Dec 18;22(12):e23518. doi: 10.2196/23518. PMID: 33156803; PMCID: PMC7757783.

[15] Zitting KM, Lammers-van der Holst HM, Yuan RK, Wang W, Quan SF, Duffy JF. Google Trends reveals increases in internet searches for insomnia during the 2019 coronavirus disease (COVID-19) global pandemic. J Clin Sleep Med. 2021 Feb 1;17(2):177-184. doi: 10.5664/jcsm.8810. PMID: $32975191 ;$ PMCID: PMC7853234.

[16] Rovetta A. Reliability of Google Trends: Analysis of the Limits and Potential of Web Infoveillance During COVID-19 Pandemic and for Future Research. Front Res Metr Anal. 2021 May 25;6:670226. doi: 10.3389/frma.2021.670226. PMID: 34113751; PMCID: PMC8186442. 
[17] Rovetta A, Castaldo L. A new infodemiological approach through Google Trends: longitudinal analysis of COVID-19 scientific and infodemic names in Italy. BMC Med Res Methodol. 2022 Jan 30;22(1):33. doi: 10.1186/s12874-022-01523-x. PMID: 35094682; PMCID: PMC8801192.

[18] Sato K, Mano T, Iwata A, Toda T. Need of care in interpreting Google Trends-based COVID-19 infodemiological study results: potential risk of false-positivity. BMC Med Res Methodol. 2021 Jul 18;21(1):147. doi: 10.1186/s12874-021-01338-2. PMID: 34275447; PMCID: PMC8286439.

[19] The Black List. Bufale.net. URL: https://www.bufale.net/the-black-list-la-lista-nera-del-web/ [accessed 2022-02-04]

[20] Pierri F, Artoni A, Ceri S. Investigating Italian disinformation spreading on Twitter in the context of 2019 European elections. PLoS One. 2020 Jan 17;15(1):e0227821. doi: 10.1371/journal.pone.0227821. PMID: 31951628; PMCID: PMC6968875.

[21] Anche la FNOMCeO a Più libri più liberi. FNOMCeO. URL: https://portale.fnomceo.it/anche-lafnomceoa-piu-libri-piu-liberi/ [accessed 2022-02-04]

[22] Corso di aggiornamento “Pre-occupiamoci del rischio: Non solo Covid-19: I'importanza della vaccinazione nell'attuale emergenza". FNOMCeO. URL: https://portale.fnomceo.it/corso-diaggiornamento-pre-occupiamoci-del-rischio-non-solo-covid-19-limportanza-della-vaccinazionenellattuale-emergenza/

[23] Italy: Coronavirus Pandemic Country Profile. Our World in Data. URL: https://ourworldindata.org/coronavirus/country/italy [accessed 2022-02-07]

[24] Fagerland MW. t-tests, non-parametric tests, and large studies--a paradox of statistical practice? BMC Med Res Methodol. 2012 Jun 14;12:78. doi: 10.1186/1471-2288-12-78. PMID: 22697476; PMCID: PMC3445820.

[25] Joinpoint Trend Analysis Software v.4.9.0.0. (2021). URL: https://surveillance.cancer.gov/joinpoint/ [accessed 2021-08-17]

[26] Greenland S, Hofman A. Multiple comparisons controversies are about context and costs, not frequentism versus Bayesianism. Eur J Epidemiol. 2019 Sep;34(9):801-808. doi: 10.1007/s10654019-00552-z. PMID: 31522327; PMCID: PMC6759655.

[27] Rovetta A, Castaldo L. "Are We Sure We Fully Understand What an Infodemic Is? A Global Perspective on Infodemiological Problems." SocArXiv preprint. 2022 Jan 18. doi: 10.31235/osf.io/xw723.

[28] Quadros S, Garg S, Ranjan R, Vijayasarathi G, Mamun MA. Fear of COVID 19 Infection Across Different Cohorts: A Scoping Review. Front Psychiatry. 2021 Sep 7;12:708430. doi: 10.3389/fpsyt.2021.708430. PMID: 34557117; PMCID: PMC8453018.

[29] Pandemic fatigue Reinvigorating the public to prevent COVID-19. World Health Organization (WHO). URL: https://apps.who.int/iris/bitstream/handle/10665/335820/WHO-EURO-2020-116040906-55390-eng.pdf [accessed 2022-02-09]

[30] Infodemic. World Health Organization (WHO). URL: https://www.who.int/healthtopics/infodemic [accessed 2022-02-09] 
[31] Troiano G, Nardi A. Vaccine hesitancy in the era of COVID-19. Public Health. 2021 May;194:245251. doi: 10.1016/j.puhe.2021.02.025. Epub 2021 Mar 4. PMID: 33965796; PMCID: PMC7931735.

[32] Luo F, Ghanei Gheshlagh R, Dalvand S, Saedmoucheshi S, Li Q. Systematic Review and MetaAnalysis of Fear of COVID-19. Front Psychol. 2021 Jun 11;12:661078. doi: 10.3389/fpsyg.2021.661078. PMID: 34177712; PMCID: PMC8231929.

[33] Siegrist M, Luchsinger L, Bearth A. The Impact of Trust and Risk Perception on the Acceptance of Measures to Reduce COVID-19 Cases. Risk Anal. 2021 May;41(5):787-800. doi: 10.1111/risa.13675. Epub 2021 Jan 12. PMID: 33438218; PMCID: PMC8014821.

[34] Rovetta A. The Impact of COVID-19 on Conspiracy Hypotheses and Risk Perception in Italy: Infodemiological Survey Study Using Google Trends. JMIR Infodemiology. 2021 Aug 6;1(1):e29929. doi: 10.2196/29929. PMID: 34447925; PMCID: PMC8363126.

[35] Megías A, Cándido A, Maldonado A, Catena A. Neural correlates of risk perception as a function of risk level: An approach to the study of risk through a daily life task. Neuropsychologia. 2018 Oct;119:464-473. doi: 10.1016/j.neuropsychologia.2018.09.012. Epub 2018 Sep 20. PMID: 30244003.

[36] Tversky A, Kahneman D. A heuristic for judging frequency and probability. Cogn Psychol. 1973;5(2):207-232. doi: 10.1016/0010-0285(73)90033-9.

[37] Douglas KM, Sutton RM, Cichocka A. The Psychology of Conspiracy Theories. Curr Dir Psychol Sci. 2017 Dec;26(6):538-542. doi: 10.1177/0963721417718261. Epub 2017 Dec 7. PMID: 29276345; PMCID: PMC5724570.

[38] Internet usage in Italy - statistics \& facts. Statista. URL: https://www.statista.com/topics/4217/internet-usage-in-italy/\#topicHeader wrapper [accessed 2022-02-09]

[39] Individuals using the Internet (\% of population) - Italy. The World Bank. URL: https://data.worldbank.org/indicator/IT.NET.USER.ZS?locations=IT [accessed 2022-02-09]

[40] Search engines ranked by market share in Italy 2021. Statista. URL: https://www.statista.com/statistics/623043/search-engines-ranked-by-market-share-in-italy/ [accessed 2022-02-09]

[41] Share of Italian population using the internet everyday 2020, by age and gender. Statista. URL: https://www.statista.com/statistics/552767/share-of-population-using-the-internet-everyday-byage-and-gender-italy/ [accessed 2022-02-09]

\section{Acknowledgements}

I thank Dr. Lucia Castaldo for pointing out the possible role of COVID-19 infections as confounding factors regarding the queries on the cancellation of vaccination reservations. 


\section{Author information}

\section{Affiliations}

R\&C Research, Research and Disclosure, Bovezzo (BS), Italy.

\section{Contributions}

The author confirms sole responsibility for the following: study conception and design, data collection, analysis and interpretation of results, and manuscript preparation.

\section{Data availability statement}

Data available within the article, its supplementary materials, and public domain resources.

\section{Additional Information}

The authors declare no competing interests. 


\section{Appendix: Supplementary File 1}

K1: Sara Cunial. The Member of the Italian Chamber of Deputies is openly no-vax and has spread numerous fake news on the damage of COVID-19 vaccines.

Examples and sources:

- https://facta.news/notizia-falsa/2021/05/27/queste-affermazioni-di-sara-cunial-suefficacia-e-tossicita-dei-vaccini-sono-false/

- $\quad$ https://www.bufale.net/buco-nellacqua-per-sara-cunial-con-il-grafene-nel-vaccino-pfizerstudio-inconsistente/

- https://www.bufale.net/facebook-dice-basta-a-sara-cunial-oscurata-la-sua-pagina-a-forteindirizzo-novax/

- https://www.bufale.net/scatenata-sara-cunial-con-numeri-su-pfizer-mai-verificati-limetteremo-al-rogo-vi-do-il-cellulare/

- https://www.adnkronos.com/covid-la-no-vax-cunial-tenete-lontane-da-bimbi-le-vostremani-avide Bh5mtH2tShB8bZbApdaFm

- https://tg24.sky.it/politica/2021/11/25/sara-cunial-deputata-green-pass

K2: Nicola Porro. The journalist showed a strong bias in selecting sources and reading data, mentioning only news that corroborated his thinking, and ignoring the vast literature disproving his conspiracy hypotheses (e.g., COVID-19 vaccines damage, COVID-19 home therapy).

Examples and sources:

- https://www.nicolaporro.it/caro-porro-dopo-la-terza-dose-sto-peggio-che-dopo-il-covid/

- https://www.butac.it/porro-becchi-zibordi-vaccino-covid/

- https://www.butac.it/verita-si-vax/

- https://www.nicolaporro.it/caro-porro-la-vera-peste-e-negare-di-avere-fallito-sul-covid/

- https://www.nicolaporro.it/la-verita-sui-numeri-dei-no-vax-in-pericolo/

- https://www.nicolaporro.it/no-vax-e-no-cure-il-nuovo-mostro-inventato-dai-media/

- https://www.nicolaporro.it/tutto-quello-che-non-vi-dicono-sui-vaccini/

- https://www.nicolaporro.it/tutte-le-balle-sul-covid/

- https://www.nicolaporro.it/vi-racconto-le-storie-delle-vittime-dei-vaccini/

- https://www.nicolaporro.it/vaccini-a-mrna-nuovo-allarme-dei-cardiologi-usa/

- https://www.nicolaporro.it/cure-domiciliari-un-nuovo-studio-conferma-che-funzionano/

- https://www.ncbi.nlm.nih.gov/pmc/articles/PMC8479410/

- https://www.ncbi.nlm.nih.gov/pmc/articles/PMC7404088/

- https://twitter.com/butacit/status/1479860006132539402

- https://www.nicolaporro.it/virus-in-laboratorio-nuovi-indizi-in-un-video/ 
K3: Stefano Montanari. The researcher shared numerous fake news and studies harshly criticized by the scientific community regarding vaccines. Furthermore, it has repeatedly trivialized the COVID19 risk and supported epidemiologically harmful behaviors (e.g., no mask).

Examples and sources:

- $\quad$ https://www.pattoperlascienza.it/2020/03/25/coronavirus-abbiamo-denunciato-stefanomontanari/

- https://www.consiglio.basilicata.it/consiglio-api//file/1092/234981

- https://www.bufale.net/youtube-dice-basta-e-rimuove-lintervista-di-red-ronnie-a-stefanomontanari-su-temi-novax/

- https://www.tandfonline.com/doi/full/10.1080/13669877.2020.1871058

- https://www.ncbi.nlm.nih.gov/pmc/articles/PMC8601032/

K4: Luc Montagnier. The scientist supported no-vax and conspiracy theorists about COVID-19 (e.g., SARS-CoV-2 arises from the voluntary modification of HIV).

Examples and sources:

- https://www.ncbi.nlm.nih.gov/pmc/articles/PMC7459609/

- https://www.ncbi.nlm.nih.gov/pmc/articles/PMC8601032/

- https://www.jmir.org/2020/8/e20673/

- https://epjdatascience.springeropen.com/articles/10.1140/epjds/s13688-021-00301-x

K5: Alessandro Meluzzi. The psychiatrist and TV character was suspended from the Turin Medical Association because he did not vaccinate against COVID-19. Furthermore, he supports unfounded conspiracy and no-vax COVID-19 hypotheses.

Examples and sources:

- https://www.adnkronos.com/covid-meluzzi-sospeso-da-ordinemedici 6kSJZ3jTNkh9UMjEPti3iF

- https://www.butac.it/riaperture-chiusure-uk/

- https://www.butac.it/meluzzi-vaccini-covid/

- https://www.leggo.it/italia/cronache/alessandro meluzzi microchip nascosti nelle masc herine ultime notizie-5332290.html?fbclid=IwAR31pTdTkU9376zlbZHIwjY0v2jT64yHzMzqWbbVa9qIWha4GoAvxQQuiO

- https://www.ilmattino.it/societa/persone/alessandro meluzzi microchip nascosti nelle mascherine ultime notizie-5332379.html 
K6: Diego Fusaro. The columnist openly supports conspiracy and no-vax positions on COVID-19.

Examples and sources:

- https://www.butac.it/fusaro-matematica/

- https://www.butac.it/fusaro-e-le-prove-dei-complotti/

- https://www.bufale.net/diego-fusaro-dimostra-involontariamente-lefficacia-dei-vaccini/

- https://www.repubblica.it/politica/2021/12/27/news/covid vaccini diego fusaro twitter svarione numeri tamponi positivi-331793048/

- https://twitter.com/diegofusaro/status/1340651694636544001?lang=en

- https://www.bufale.net/youtube-dice-basta-a-diego-fusaro-sospesi-abbonamenti-e-tutti-isuoi-guadagni/

- https://twitter.com/DiegoFusaro/status/1490315407135236099

- https://www.bufale.net/erroraccio-diego-fusaro-vaccini-sminuiti-con-the-lancet-maignora-le-breakthrough-infections/

K7: Barbara Balanzoni. The doctor has spread dangerous fake news about COVID-19 vaccines and therapies. She was suspended from the Order of Doctors of Venice.

Examples and sources:

- $\quad$ https://www.bufale.net/il-comune-di-bugliano-obbliga-cani-e-novax-a-casa-capodannobarbara-balanzoni-ci-ricasca/

- https://www.bufale.net/barbara-balanzoni-crede-al-messaggio-ai-non-vaccinati-delcomune-di-bugliano-Iha-presa-male/

- https://www.butac.it/i-morti-di-serie-z-post-vaccino-ovviamente/

- $\quad$ https://twitter.com/barbarab1974/status/1399431116088610819

- https://www.bufale.net/verso-la-sospensione-di-barbara-balanzoni-dallordine-dei-medicivenezia-assente-allaudizione/

- https://corrieredelveneto.corriere.it/venezia-mestre/cronaca/22 gennaio 21/dottoressano-vax-sospesa-dall-ordine-continuero-curare-miei-pazienti-46d893d2-7acb-11ec-9fc0f958588bb295.shtml

- https://www.huffingtonpost.it/covid/2022/01/22/news/dottoressa no vax sospesa conti nuero a curare | ordine non puo impormi niente -7554447/

- https://www.bufale.net/richiesta-la-radiazione-per-barbara-balanzoni-si-attivaufficialmente-laadi/

- https://www.bufale.net/nel-2020-barbara-balanzoni-inveiva-verso-i-novax-pentaidioti-dapsicosette/

K8: Italian entrepreneur. Since he is not a public character, personal information has not been reported. The name was found by consulting the Google Trends "related queries." This person supports conspiracy theories about COVID-19 on his Twitter personal page. 
K9: ByoBlu. This source is known for sharing conspiracy news and is a constant source of COVID-19 disinformation.

Examples and sources:

- https://pubmed.ncbi.nlm.nih.gov/34447925/

- https://www.ncbi.nlm.nih.gov/pmc/articles/PMC8601032/

- https://www.ncbi.nlm.nih.gov/pmc/articles/PMC6968875/

- https://www.butac.it/reazioni-avverse-vaccini-covid-europa/

- https://www.bufale.net/provvedimento-pesante-e-byoblu-chiuso-da-youtube-il-canale-dimessore-non-ce-piu/

- $\quad$ https://www.bufale.net/youtube-dice-basta-con-byoblu-e-claudio-messora-stop-a-tempoper-disinformazione-sul-vaccino/

K10: Maurizio Blondet. The Italian journalist is historically known for his conspiracy positions (also on COVID-19).

Examples and sources:

- https://www.butac.it/blondet-i-francesi-e-i-vaccini-contro-covid-19/

- https://www.butac.it/blondet-la-proteina-spike-e-le-fonti/

- https://www.butac.it/correlazione-causalita-e-maurizio-blondet/

- https://facta.news/storie/2020/12/29/chi-ha-diffuso-la-disinformazione-in-italia-nel-2020/

- https://www.bufale.net/il-dottor-charles-hoffe-e-linsufficienza-cardiaca-da-siero-mrna-unconcentrato-di-disinformazione/

- https://www.bufale.net/negazionisti-che-singannano-da-soli-per-brevita-norimberga-2/

- https://www.ncbi.nlm.nih.gov/pmc/articles/PMC8363126/

K11: Francesca Donato. Italian politics supports no vax conspiracy hypotheses and shows clear bias in the analysis of the available evidence.

Examples and sources:

- https://www.bufale.net/francesca-donato-presenta-numeri-a-favore-dei-vaccini-senzavolerlo-bassetti-rincara-la-dose/

- $\quad$ https://www.repubblica.it/salute/2022/01/13/news/vaccino pfizer la bufala dell eccipie nte alc-0315 nocivo per I uomo-333677906/ 
- https://www.bufale.net/insinuazioni-di-francesca-donato-su-david-sassoli-e-vaccini-florisle-chiude-il-microfono/

- https://www.bufale.net/sbrocca-pregliasco-quando-francesca-donato-cita-i-cosiddettivaccini-bufale-e-paroloni-su-la7/

- https://www.bufale.net/pfizer-ha-utilizzato-la-sostanza-alc-0315-nel-suo-vaccino-ed-enociva-per-luomo-non-e-cosi/

- https://www.butac.it/donato-immunita-sterilizzante/

K12: Aldo Maria Valli. The journalist supports COVID-19 conspiracy hypotheses and shows clear bias in source selection. Furthermore, he invites readers to engage in dangerous behaviors (e.g., ignoring the vaccination obligation).

Examples and sources:

- https://www.aldomariavalli.it/2021/09/01/intervista-ecco-perche-io-medico-immunologosono-contro-la-vaccinazione-a-tappeto-e-contesto-tutta-la-strategia-anti-covid/

- https://www.aldomariavalli.it/2022/02/04/la-pandemia-e-i-principi-di-manipolazionedelle-masse-di-goebbels/

- https://www.aldomariavalli.it/2022/02/06/vademecum-per-over-cinquanta-comerispondere-alla-sopraffazione/

- https://www.aldomariavalli.it/2022/02/06/covid-e-numeri-gonfiati-ecco-come-in-italia-ein-usa-i-positivi-sono-diventati-business/

- $\quad$ https://www.aldomariavalli.it/2020/07/15/il-covid-e-dopo-untori-transumani-per-ilnuovo-ordine-mondiale/

K13: Marco Tosatti. The journalist shares conspiracy hypothesis about health dictatorship and misinformation about COVID-19, including vaccines.

Examples and sources:

- https://www.bufale.net/anche-vigano-ci-parla-del-great-reset-2021-i-3-concetti-oltre-lasolita-dittatura-sanitaria/

- https://www.marcotosatti.com/2021/11/06/se-lepidemia-dei-non-inoculati-e-una-bufalala-verita-smentisce-il-cts/

- https://www.marcotosatti.com/2021/11/12/il-numero-dei-ricoverati-con-coronaviruscifre-e-ragionamenti/

- https://www.marcotosatti.com/2021/08/09/in-che-modo-i-vaccini-covid-19-sonocorrelati-allaborto/

- https://www.marcotosatti.com/2021/08/02/le-cifre-reali-della-mortalita-da-vaccini-iltabu-svelato-da-uno-studio-francese/

K14: Imola Oggi. The website intentionally spreads fake news about COVID-19 and vaccines. 
Examples and sources:

- https://www.butac.it/imola-oggi-e-le-dichiarazioni-di-brusaferro/

- https://www.butac.it/imola-oggi-allattamento/

- https://www.butac.it/imola-oggi-movimento-italia-nel-cuore-e-il-bmi/

- https://www.butac.it/sinagra-imola-oggi-medici/

- https://www.bufale.net/gia-risolto-il-mistero-dei-vaccinati-positivi-in-area-no-covid-alriuniti-di-foggia-complottisti-ancora-in-ritardo/

- $\quad$ https://www.bufale.net/il-vaccino-obbligatorio-non-viola-il-codice-di-norimberga-lutilizzoimproprio-del-termine-sperimentale/

K15: Radio Radio TV. This news channel intentionally shares fake news about COVID-19.

Example and sources:

- $\quad$ https://www.butac.it/siete-continuamente-manipolati/

- https://www.butac.it/il-tempo-india-decessi/

- https://www.butac.it/radio-radio-grafici/

- https://www.butac.it/radio-radio-aifa/

- https://facta.news/storie/2020/06/17/che-cosa-e-successo-tra-youtube-e-radio-radio/

- https://www.bufale.net/erroraccio-diego-fusaro-vaccini-sminuiti-con-the-lancet-maignora-le-breakthrough-infections/

- $\quad$ https://www.bufale.net/dal-no-mask-e-no-vax-di-daniela-martani-alle-5-somministrazioniprima-dellisola-dei-famosi/

K16: Massimo Mazzucco. The Italian filmmaker and blogger supports conspiracy hypotheses on COVID-19 and vaccines.

Example and sources:

- $\quad$ https://www.bufale.net/non-fate-il-vaccino-per-il-coronavirus-sciocchezze-complottistespiegate-con-larticolo-32/

- https://www.butac.it/mazzucco-le-cure-proibite/

- https://www.butac.it/antivaccinisti-e-covid19/

- https://www.butac.it/quantum-dot-tattoo-vaccini-e-allarmismo/

- https://www.butac.it/mazzucco-la-disinformazione-e-il-covid-19/

- https://www.open.online/2021/05/20/covid-19-le-cure-proibite-documentariocomplottista-massimo-mazzucco/ 
- https://facta.news/notizia-falsa/2021/01/05/questi-esperimenti-con-la-frutta-nondimostrano-che-i-tamponi-rapidi-sono-inattendibili/

K17: Luogocomune. The website intentionally spreads fake news about COVID-19 and vaccines. This website is managed by Massimo Mazzucco (K16).

Examples and sources:

- $\quad$ https://24plus.ilsole24ore.com/art/perche-non-bisogna-credere-re-video-complottistivirus-ADLammF

- https://luogocomune.net/info-sito 